\title{
Łs̄quemas operativós laminares en el Musteriense final de la Cueva del Castillo (Puente Viesgo, Cantabria)
}

\author{
V. Cabrera Valdés ${ }^{1}$, J.M. Maillo fernández ${ }^{2}$, F. Bernaldo de Quirós ${ }^{3}$
}

\section{RESUMEN ABSTRACT}

Se presentan una serie de evidencias de la presencia de esquemas operativos

laminares y microlaminares en los

niveles musterienses de la Cueva del Castillo. Su presencia confirma nuestras

hipótesis relativas a la transición del

Paleolítico Medio al Superior en la Region Cantábrica y refuerza la idea del papel de los Neandertales en las transformaciones culturales que dieron lugar al Auriñaciense.

\section{PALABRAS CLAVE}

Paleolítico Medio, Paleolítico Superior, Musteriense, Auriñaciense, Método laminar, El Castillo. Tecnología.
We present here some evidences of the blade/bladelet production in Mousterian levels of Cueva del Castillo. This presence confirm our hypothesis in the continuity between the Middle to Upper Palaeolithic in Cantabrian Spain. Also provide us of new data on the role of Neanderthals in the Early Upper Palaeolithic and the formation of the Aurignacian.

\section{KEYWORDS}

Middle Palaeolithic, Upper Palaeolithic, Musteriense, Aurignaciar, Blade, Technology, El Castillo, Bladelet.

Departamento de Prehistoria e Historia Antigua, UNED, Madrid, vcabrera@geo.une.es.

2 Becario de FPV del MECD, Departamento de Prehistoria e Historia Antigua, UNED, Madrid, chonchi36@hotmail.com.

3 Área de Prehistoria, Universidad de León, León. dectbq@unileon.es. 


\section{INTRODUCCION}

La presencia de producción laminar es ya un hecho contrastado en el Paleolítico Medio. Sus primeros descubrimientos en los niveles de la Cueva de Yabrud sirvió en primer lugar de base para definir el "protoauriñaciense" (Rust, 1950, Bordes, 1977) y sustentar las ideas difusionistas sobre el origen del Auriñaciense europeo. A partir de los años 80 se empezaron a descubrir evidencias de esta tecnología en diversos yacimientos en el norte de Francia y sur de Bélgica (Riencourt, Seclin, Rocourt, etc. (Reveillon y Tuffreau, 1994)) con lo que su presencia, en principio esporádica, se convirtió en algo habitual. La existencia de hojas no es un hecho extraño en el Musteriense, pues su presencia ya era recogida en las propuestas tecno-tipológicas de $\mathrm{F}$. Bordes (1980) al establecer el denominado "Indice Laminar", aunque la mayoría de dichas hojas se obtenían mediante variantes de la técnica Levallois. El interés de los descubrimientos de los últimos años se ha situado en la constatación de la existencia de varias técnicas para la producción de hojas, incluyendo las características del Paleolítico Superior. Su distribución también se ha ampliado con yacimientos en Alemania (Rheindalen (Bosinski, 1966), Tönchesberg (Conard, 1990), Ucrania (Cabaj, Sitlivyj 1994), sin olvidar su presencia en el Próximo Oriente (Meigen 1994, Marks 1992). Su cronología comienza en los EIO 8 a 6 con un mayor desarrollo entre los EIO 5 y 4 . Las técnicas de producción laminar son variadas, desde la Levallois de hojas, la producción directa a partir de cantos, así como una producción laminar a partir de núcleos prismáticos a debitage semi-tournant o a debitage turnant (Reveillon et Cliquet 1994).

Las nuevas excavaciones de la Cueva del Castillo están aportando un importante corpus de datos que nos han ido permitiendo establecer la existencia de una clara continuidad entre los niveles musterienses y los correspondientes al Paleolítico Superior. Estos datos nos permitieron considerar en primer lugar como la transición es mas un problema cuantitativo que cualitativo (Cabrera y Bernaldo de Quirós 1990). El estudio tecnológico de los niveles $18 \mathrm{~b}$ y $18 \mathrm{c}$ aportaron también la confirmación de la existencia, en estos niveles del Auriñaciense de transición, de cadenas técnicas de tipo recurrente centripeto y sus variantes, junto a la presencia de características cadenas laminares y microlaminares.

El estudio de los niveles correspondientes al Musteriense comenzó en 1998 tras la excavación del nivel estéril (19) que le separaba los niveles Auriñacienses (18b y 18c). El nivel 20 se corresponde con el nivel Musteriense Alfa de Obermaier (Cabrera 1984) y ha sido dividido en seis subniveles. En general mantienen las tendencias ya observadas en la excavación antigua, así en los niveles superiores 20a y 20b aparecen hen- 

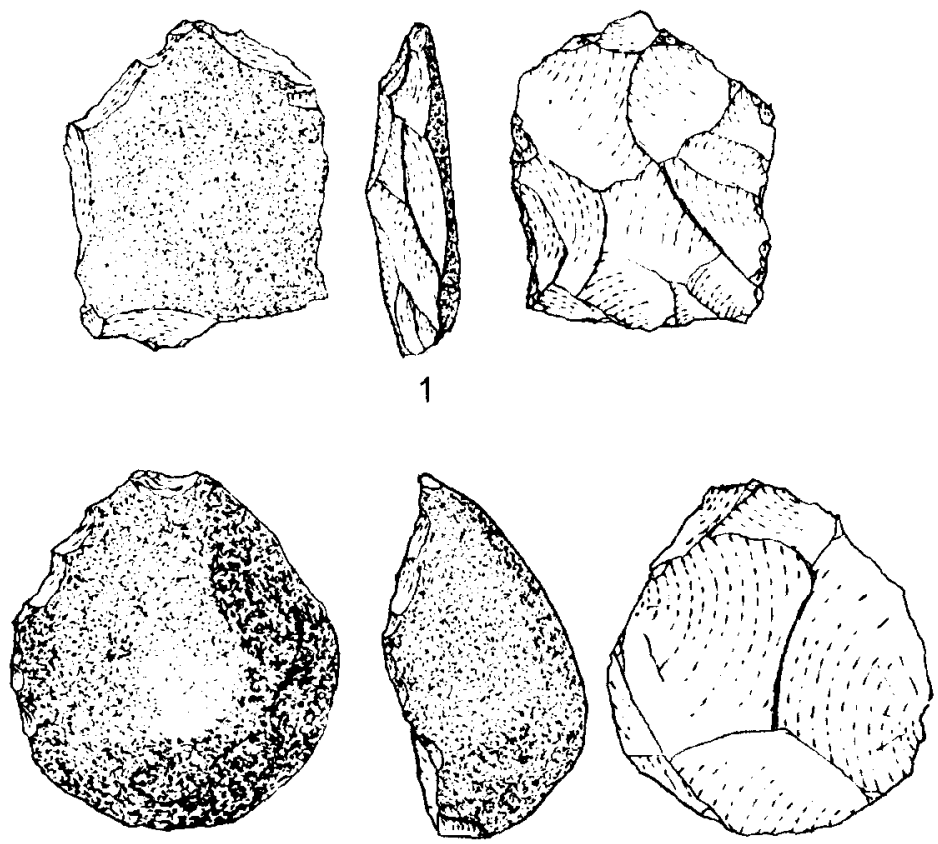

2
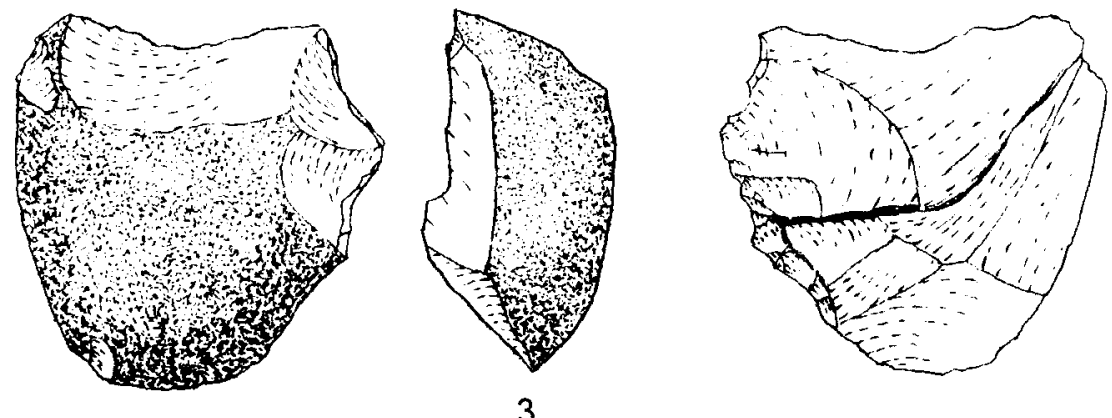

Fig. 1. Nivel 21. 
dedores tecnológica y tipogicamente semejantes a los de las primeras excavaciones, y como ellos fabricados en cuarcita y ofita. En el nivel 20c apareció un área de combustión simple que presenta en su base huellas de rubefacción. La secuencia termina con los niveles $20 \mathrm{~d}$ y $20 \mathrm{e}$ que han sido alterados térmicamente por el hogar del nivel superior, de forma que algunos de los restos de fauna son casi inidentificables, también presenta hendedores.

En la campaña del año 2000 se inicio la excavación del nivel 21a, correspondiente a la primera subvisión que hemos realizado en el nivel 21, estéril según la excavación de H. Obermaier (Cabrera, 1984). En principio este nivel presenta una gran complejidad que esperamos ir resolviendo en futuras campañas.

Los niveles musterienses de la cueva de El Castillo están caracterizados fundamentalmente por unos esquemas operativos discoides 0 Levallois recurrente centrípeto (figura 1 ), cuyos productos se emplean como raederas principalmente (figura 2 ) destacando la presencia de hen-

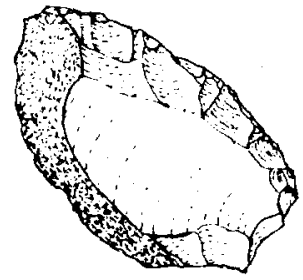

1

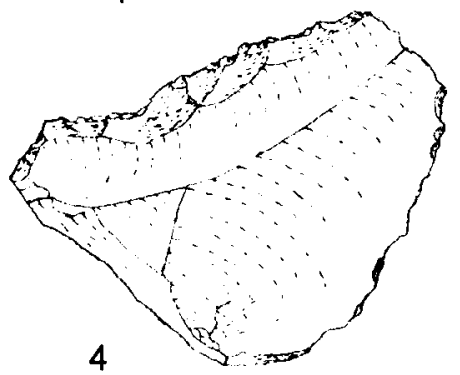

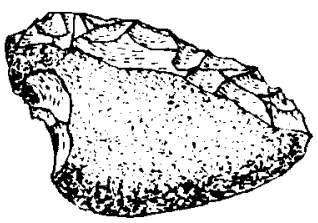

2

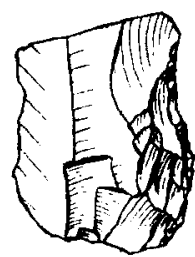

3

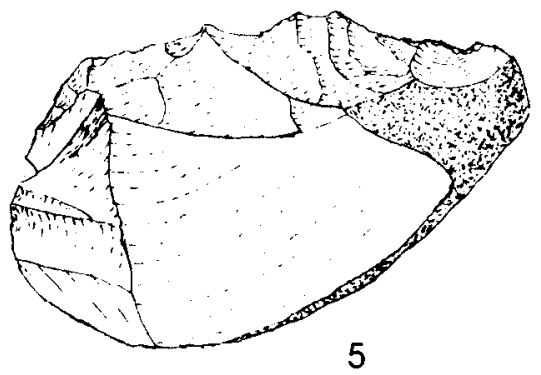

Fig. 2. Nivel 21. 

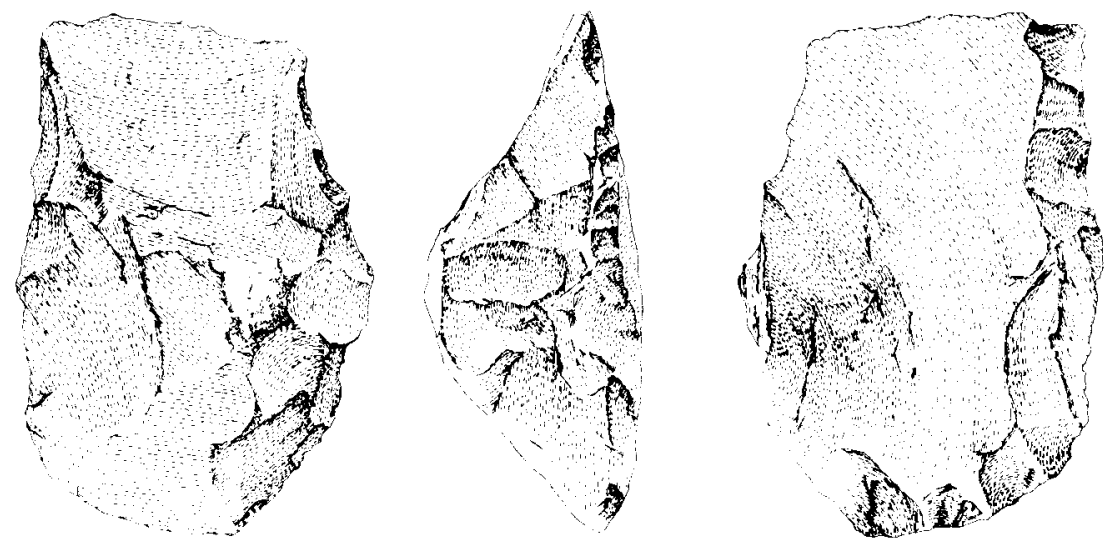

Fig. 3. Nivel 21 .

dedores (figura 3). Sin embargo junto a ellos debemos añadir los esquemas laminares que en este trabajo se presentan.

\section{ESQUEMAS OPERATIVOS LAMINARES}

Las conclusiones que se pueden extraer de este estudio son provisionales. Todos los niveles incluidos en la secuencia musteriense se encuentran en estudio y en proceso de excavación. Pero dada la importancia científica de los resultados nos lleva a presentarlos de forma preliminar.

Ante la dificultad intrínseca que conlleva el identificar estos soportes laminares de otros similares producidos por esquemas operativos de lascas (como puede resultar de la preparación de planos de percusión en núcleos discoides, Levallois, etc. en donde encontramos hojas/hojitas «de fortuna») hemos querido ser muy rigurosos e incluir como tales aquellos soportes muy característicos de esquemas laminares, es decir, aquellas piezas que presentan restos de extracciones anteriores paralelas, así como sus bordes y una preparación específica del talón (Inizan et alli, 1995). Por ello, hemos desechado aquellos ejemplares que, aunque podrían pertenecer a éstos esquemas técnicos, no ofrecieran la certeza suficiente.

Los atributos que hemos tenido en cuenta son: el tamaño del talón, la preparación del anverso (abrasión, retoque), el tipo de percusión (siempre 
que este fuese posible), la regularidad de las nervaduras y del soporte con relación a su eje tecnológico, así como la curvatura del nerfil

Algunos de los niveles estudiados no presentan núcleos, por lo que tan solo disponemos de los soportes extraídos. Para estudiar el método de talla empleado utilizaremos el remontaje mental, es decir el estudio minucioso de los negativos de la cara dorsal donde encontramos impresa la secuencia técnica de la que proviene la pieza estudiada (Tixier, 1978; Pelegrin, 1995).

\section{NIVEL 21}

\section{a) Los núcleos}

Disponemos de dos grupos claros en los núcleos de hojas/hojitas. Por un lado aquellos que son concebidos desde un primer momento para la extracción de hojas y un segundo que parece que son reconvertidos a partir de núcleos o fragmentos de núcleos de lascas. Conceptualmente ambos grupos son muy diferentes.

Grupo 1: son núcleos de jerarquización prismática unipolar y bipolar. Disponemos de tres núcleos de este grupo, dos presentan un esquema bipolar y uno unipolar (figura 4: 1-2; fig. 5). Los planos de lascado son estrechos y alargados, los flancos laterales están marcados, bien por fracturas naturales, bien por cortex al presentar una morfología adecuada.

Se realizan a partir de cantos o fragmentos de morfologías rectangulares en origen, por lo que la mise en forme no es muy intensa. Se aprovechan, siempre que es posible las superficies naturales del canto (cortex o planos naturales) para los planos de percusión, si no, se preparan con una única y gran extracción, con lo que los soportes presentan talones lisos o puntiformes. No existen negativos, ni soportes, que indiquen algún tipo de preparación preliminar de la primera extracción tipo arista de núcleo o similar. Por el contrario, creemos que debía ser una extracción tipo hoja-entame la que iniciara la secuencia de talla (figura 7: 5; fig. 8: 13), el cintrado y carenado del núcleo es cuidado por las extracciones en sentido bipolar en uno de los ejemplares, mientras que el cintrado de la tabla es marcado por la convexidad natural del núcleo, que es de forma semicircular, o por negativos/fracturas anteriores. En los de gestión unipolar no existe control del carenado. La recurrencia es manifiesta en dos de los ejemplares. Ésta comienza desde uno de los lados del plano de lascado, por lo que el soporte extraído será una hoja u hojita con cortex en uno de sus laterales. Siendo a la vez una pieza predeterminada (man- 


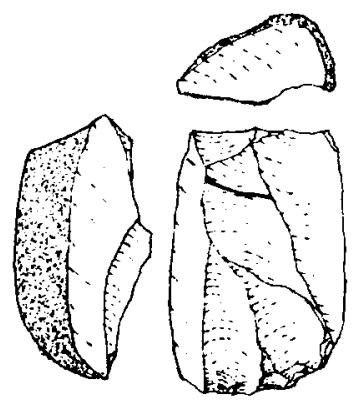

1
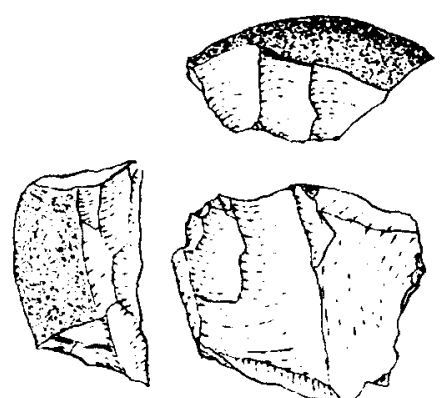

3

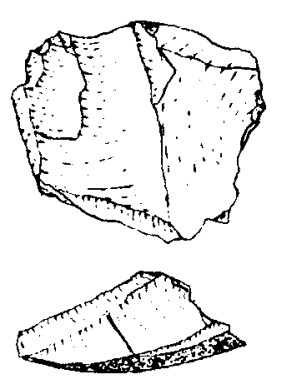

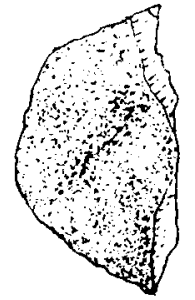
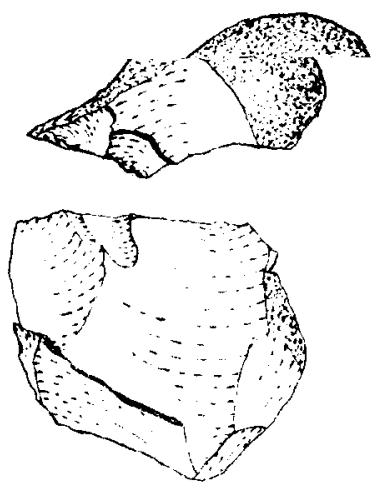

2
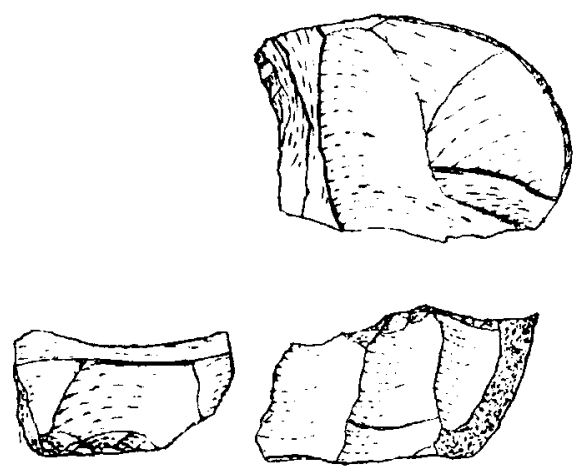

4

Fig. 4. Nivel 21.

tiene las expectativas morfo-técnicas deseadas) y predeterminante (modifica el carenado del plano de lascado) como son las piezas representadas en las figuras $6: 5,7,11$; fig. $7: 1,7-10$.

Grupo 2: son núcleos cuyos soportes han sido núcleos o son fragmentos de los mismos. Por esta razón, no presentan una caracterización muy clara, al convivir los negativos de la antigua y la moderna cadena operativa. Aún con esto, el "modo" de explotación es más oportunista y menos estandarizado que el anterior grupo. La mise en 
forme es poco compleja o casi inexistente. Se toma como plano de percusión alguno de los negativos ya existentes en la pieza y que son heredados de la cadena operativa anterior. Estos planos de percusión son transversales al futuro plano de lascado. Éste presenta de forma implícita los requerimientos básicos de convexidad y cintrado adecuados para la talla de hojas/hojitas. Es por ello, por lo que no se efectúa, al menos no tenemos evidencias, ningún tipo de arista o neoarista de núcleo. El resto de la mise en forme resulta igual de expeditiva (no existen aristas laterales, semitabletas, flancos de núcleo, etc.) y el entretenimiento de los mismos es prácticamente nulo. En lo referente a la fase de producción comentar que debido a la "pobre» mise en forme la recurrencia de las series es baja, limitándose a una o dos series. El oportunismo que venimos describiendo queda patente en dos de los núcleos en los que existen dos planos de percusión y dos planos de lascado independientes que siguen el esquema arriba descrito (figura 4: 3-4).
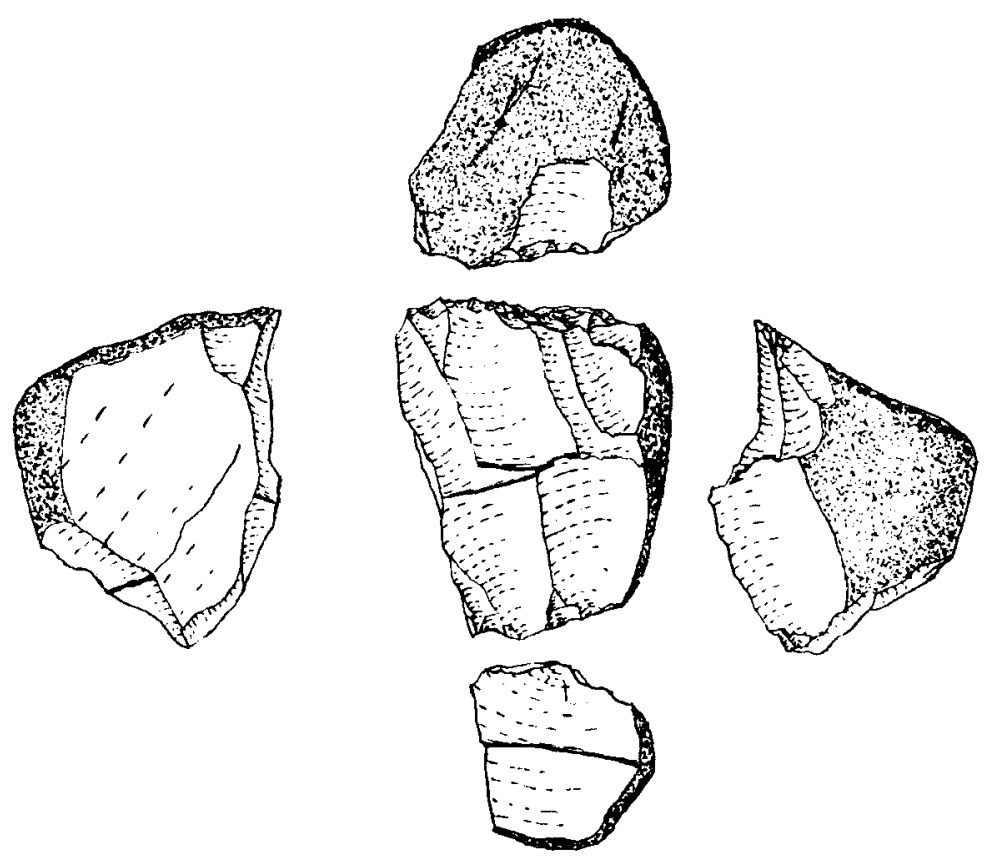

Fig. 5. Nivel 21. 

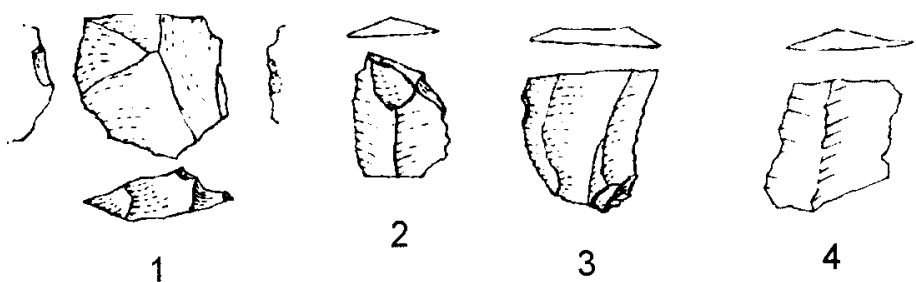

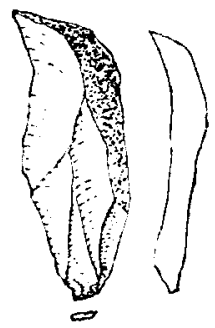

5

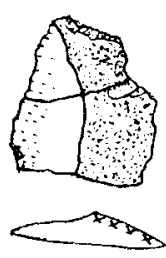

9

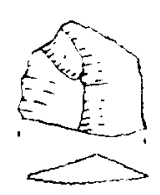

13

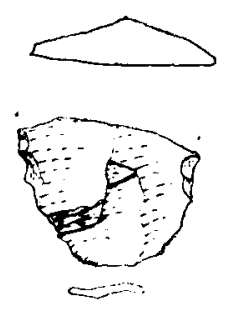

6
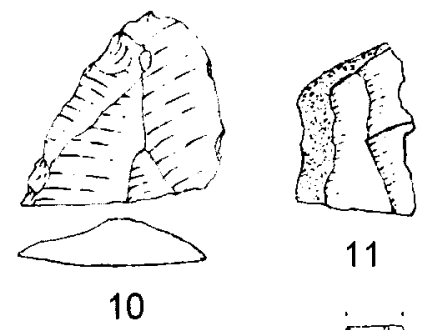

11

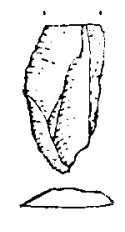

15

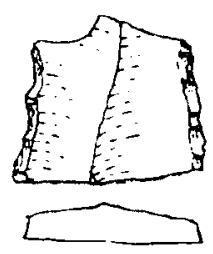

8

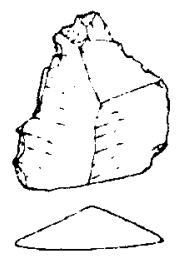

12

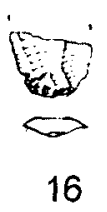

Fig. 6. Nivel 21. 


\section{b) Los soportes}

La mayoría de los soportes estudiados corresponden a hojitas (figuras 6 y 7). Aunque muchos se encuentran fracturados. El estudio de sus características morfológicas nos permite adscribirlo a esquemas técnicos laminares.

Los soportes que son extraídos mediante los núcleos del grupo 1 se caracterizan por poseer las nervaduras paralelas al eje tecnológico, al igual que la dirección de las extracciones anteriores. Los talones son en su mayoría lisos o puntiformes con preparación en el anverso mediante retoque y abrasión. Son soportes de rectitud buena y su morfología tiende a ser rectangular en la mayoría de los casos.

Los soportes extraídos con los núcleos del grupo 2 son similares. Pero, al menos en las primeras series, pueden ser poco característicos y ser hojitas atípicas al no presentar los requerimientos tecnológicos adecuados o característicos a causa de los negativos ya existentes de la anterior cadena operativa. Aspecto que va desapareciendo a medida que avanza la explotación del núcleo.

\section{c) Útiles retocados}

Este nivel presenta la panoplia clásica de productos retocados que podemos encontrar en las ocupaciones musterienses de forma habitual (raederas, denticulados...). Sin embargo, hallamos algunos tipos que aunque no son novedad sí son relevantes, no tanto por su número, como por sus características morfológicas. Estas piezas son típicas del Paleolítico Superior, pero en este nivel toman una especial relevancia (ver figura 7: 11 y fig. 8). Entre ellos destacan los raspadores (sobre todo de tipo auriñaciense), los buriles, los perforadores y las «hojas auriñacienses" (que no son más que raederas dobles espesas).

\section{NIVEL 21 SUPERIOR}

\section{a) Soportes}

El material estudiado por el momento adscribible a un esquema técnico laminar es exiguo, aunque muy característico. Está formado en su totalidad por productos de débitage. Éstos, como ocurre en el nivel anterior, son hojas y hojitas (fragmentos en su gran mayoría) y algunos soportes resultantes de la reactivación del cintrado del núcleo (ver figura 9) 


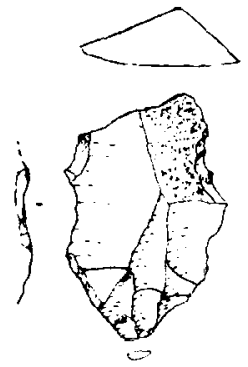

1

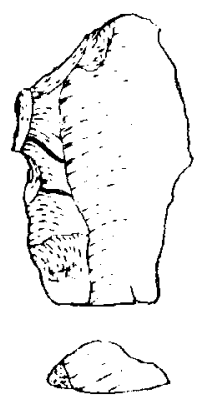

2

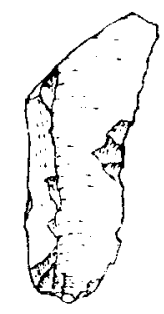

3

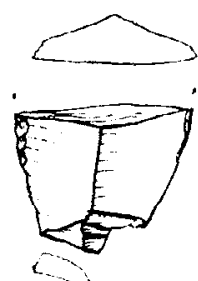

4

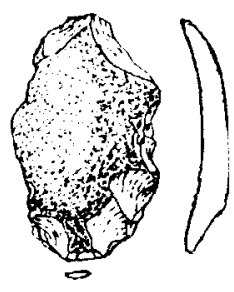

5

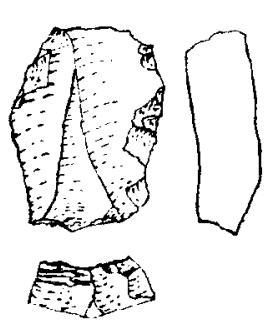

6

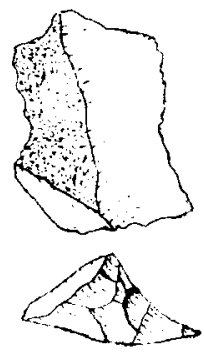

7

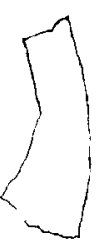

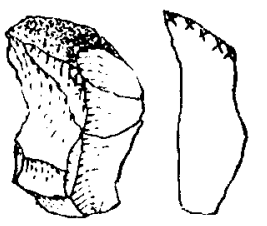

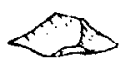

8

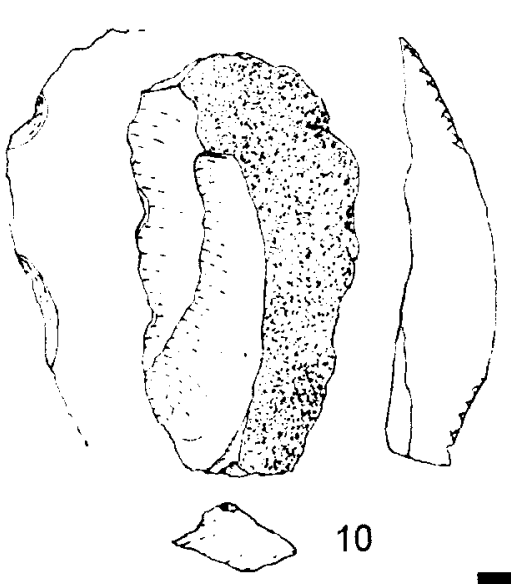

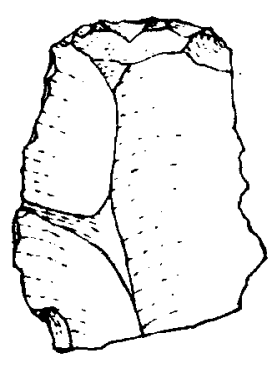

11

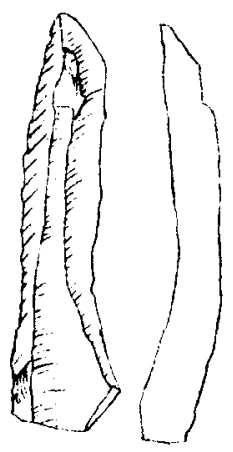

12

Fig. 7. Nivel 21. 


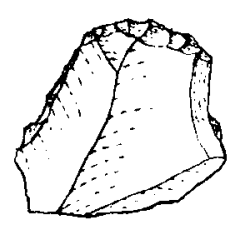

1
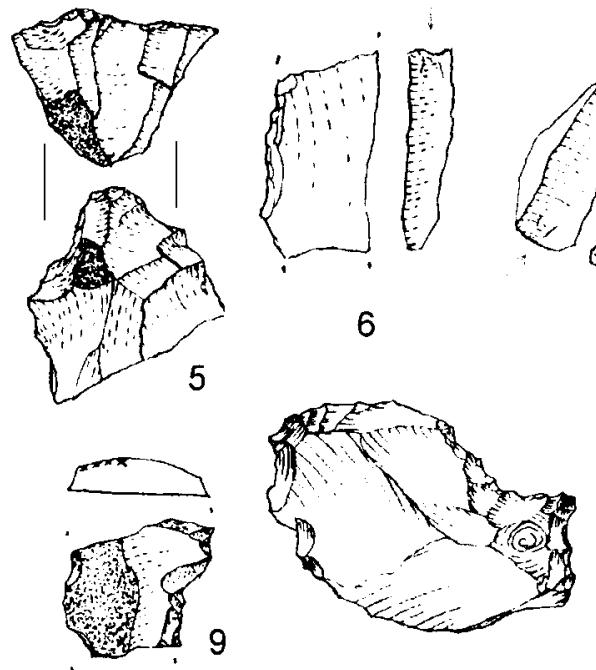

10

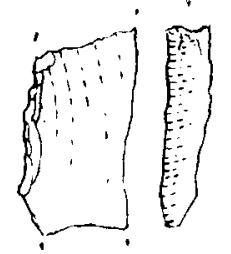

6
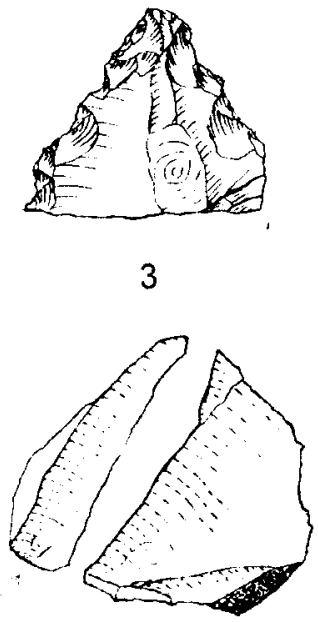

7
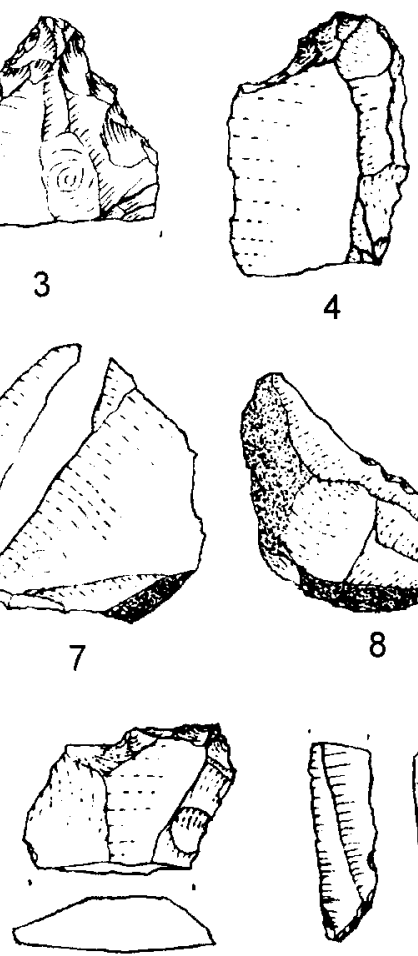

11

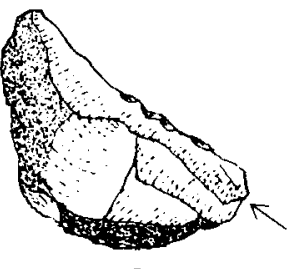

8

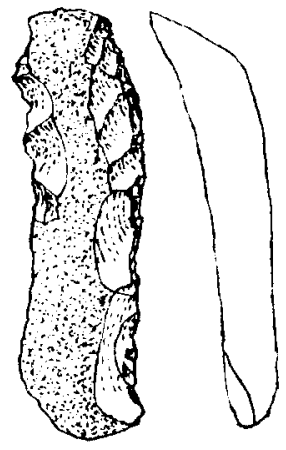

13

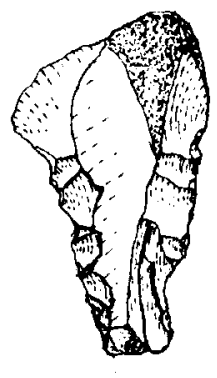

14

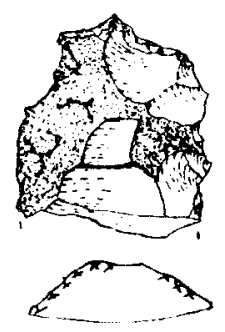

15

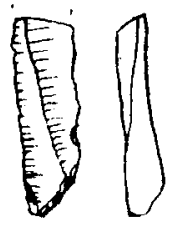

12

Fig. 8. Nivel 21. 

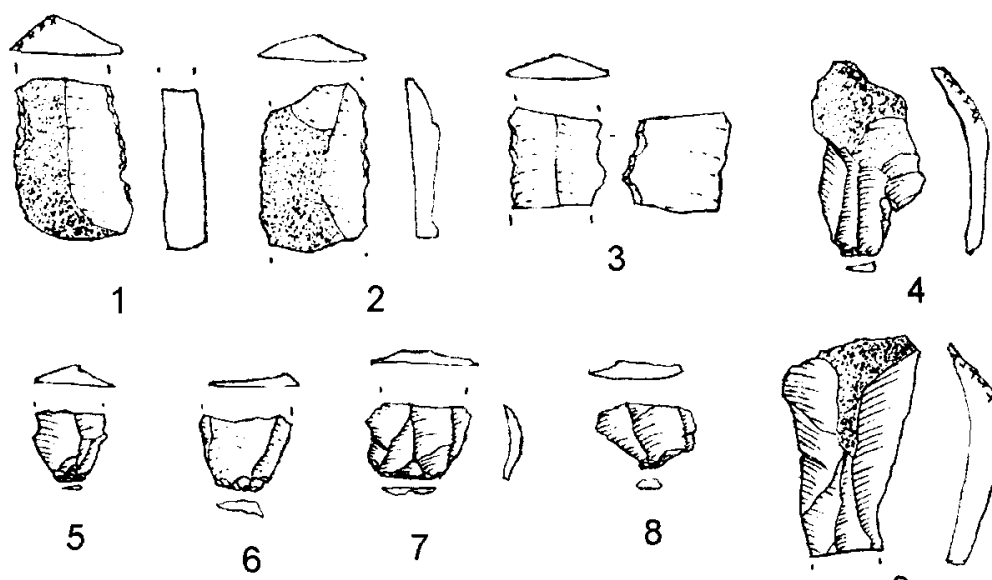

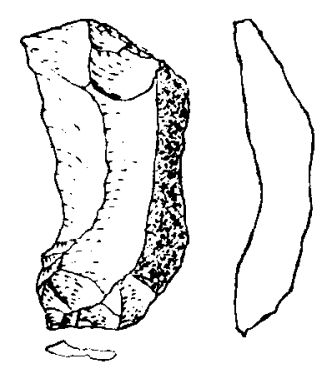

10

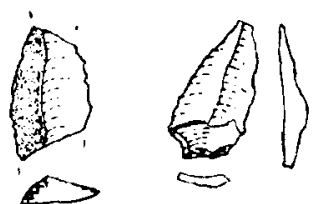

13

14
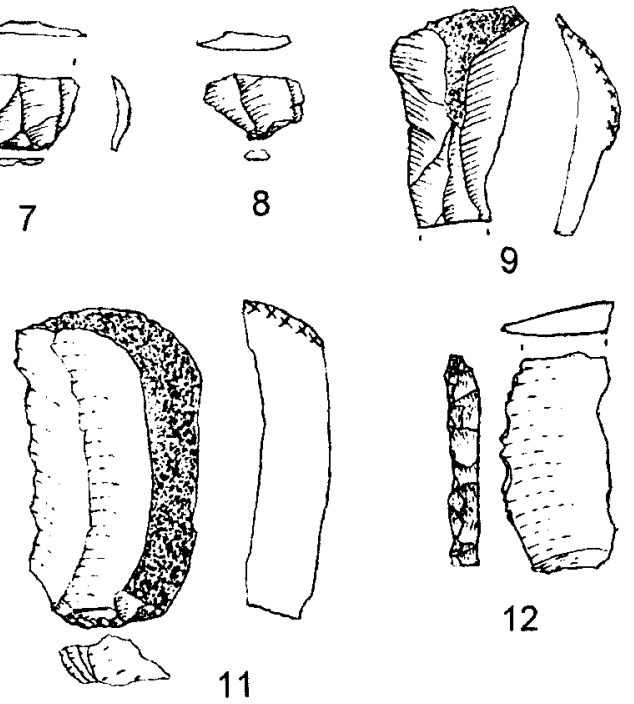

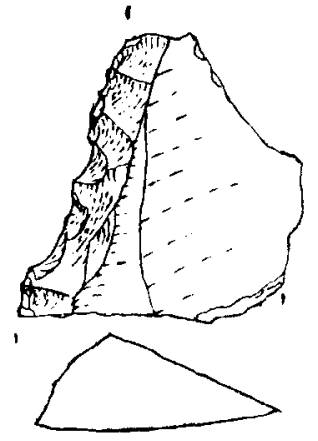

15

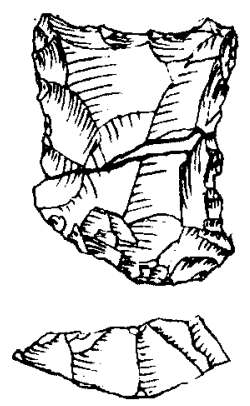

16

Fig. 9. Nivel 21 sup. 
y presentan características similares a las ya observadas en el nivel anterior: talones lisos o puntiformes, preparación del anverso, percusión directa con percutor blando...

\section{b) Útiles retocados}

Resulta interesante constatar entre el material retocado, aunque escaso y mayoritariamente musteriense, la presencia de dos hojitas retocadas: una presenta un dorso abrupto y la otra retoques semiabruptos inversos en uno de sus lados. Además de un buril y una «hoja auriñaciense» (ver figura 9: $3,12,15-16$ ).

\section{NIVEL 20e}

\section{a) Soportes}

No se han hallado por el momento núcleos encuadrables a este esquema técnico. Sin embargo, los productos son muy abundantes.

Según éstos, el esquema técnico puede ser muy similar al representado en los niveles precedentes. La mayoría son hojitas $u$ hojas de pequeño tamaño. Los planos de percusión a juzgar por los talones debían ser planos o corticales y el entretenimiento de los núcleos escaso. No tenemos constancia de semitabletas ni flancos, así como de aristas o neoaristas de núcleo. Por el contrario, encontramos alguna hoja entame y hojas de sección triangular con cortex lateral que son utilizadas para reactivar el cintrado del núcleo (figura 10: 1, 3, 5, 12, 21-23). Las hojas y hojitas de producción plena presentan las características morfo-técnicas ya comentadas en anteriores niveles destacando sobre todo el punto de impacto en los talones mediante una profusa preparación en el anverso mediante retoque y abrasión (figura 10: 2, 4, 7-11, 13-20).

\section{b) Útiles retocados}

Este nivel presenta productos retocados como los que podemos encontrar en las ocupaciones musterienses de forma habitual (raederas, denticulados...) junto a los que encontraremos otros de tipo Paleolítico Superior como los buriles y las raederas dobles que, en otro contexto, serían autenticas hojas auriñacienses (figura 10: 23). 

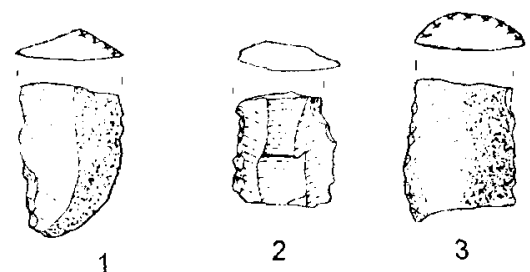

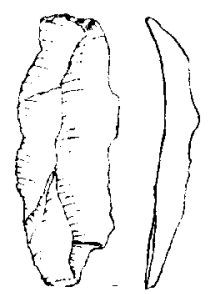

4

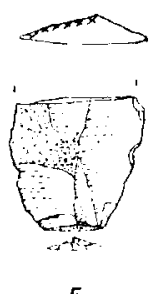

5

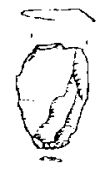

9

8

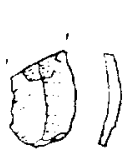

15
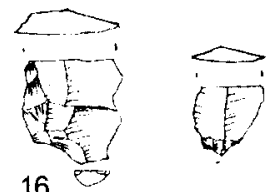

17

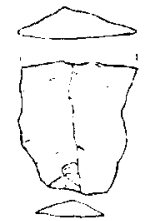

18

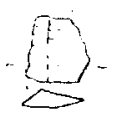

20
13

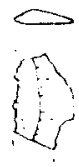

19

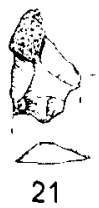

14

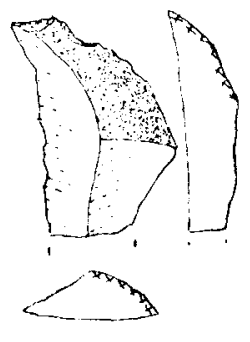

22

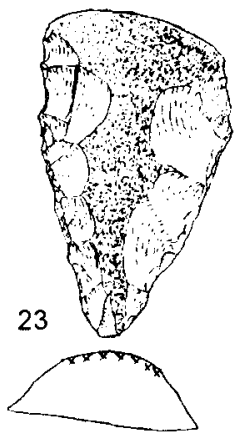

Fig. 10. Nivel 20e. 
NIVEL 20d

a) Soportes

El material es escaso. Una hoja con cortex lateral y dos hojitas de producción plena (figura 11: 4-6).

b) Útiles retocados

Tan solo disponemos de dos piezas retocadas de tipo Paleolítico Superior como son un raspador carenado y alguna raedera doble $u$ hoja auriñaciense (figura 11: 1-3).

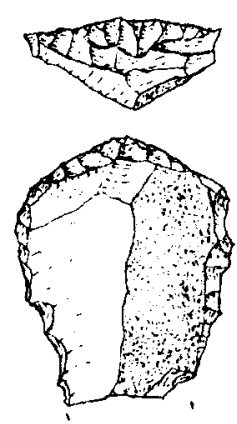

1

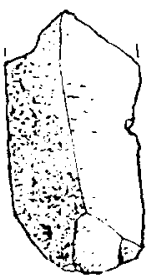

4

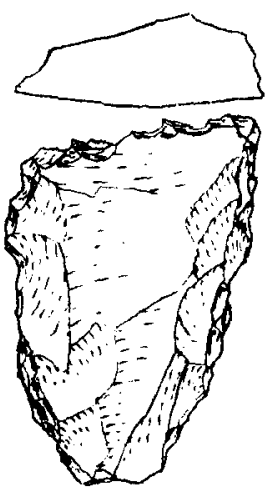

2

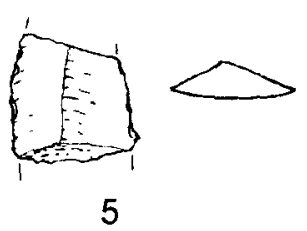

5

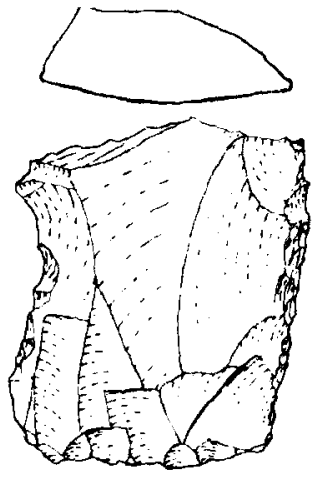

3

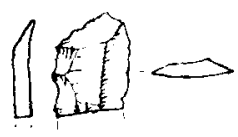

6

Fig. 11. Nivel 20d. 


\section{NIVEL 20c}

Este nivel está subdividido en varios subniveles debido a la existencia de un hogar. Los diferentes subniveles representan la estratificación del mismo. Para este estudio se han tomado como una unidad. Su nomenciatura es $20 \mathrm{c}, 20 \mathrm{c} 1 ; 20 \mathrm{c} 3 \mathrm{~b}$ y $20 \mathrm{c} 3 \mathrm{a}$.

\section{a) Núcleos}

En el nivel 20c contamos, en contra de la dinámica del resto de niveles con varios núcleos y ningún soporte. Disponemos de cinco núcleos de hojitas, todos ellos en cuarcita de grano fino. Todos presentan una gestión prismática (grupo 1), en dos casos sobre canto y sobre fragmento de núcleo en otro, que presentan explotaciones de tipo prismáticas, ya unipolares, ya bipolares.

La mise en forme está confeccionada en uno de los casos a partir de la morfología natural del nódulo empleado (ver figura 12: 1) presentando una configuración oportunista como los que estamos observando en otros niveles. Utilizando como plano de percusión una diaclasa interna del mismo. Las delimitaciones laterales de la tabla de lascado están realizadas mediante cortex y la forma semicircular del nódulo (ver figura). Los otros dos núcleos presentan una morfología un poco más compleja. Uno de ellos, de explotación prismática unipolar presenta un plano de percusión facetado (aunque de ángulo no apropiado, lo que provocó el reflejado de algunas extracciones y, a la postre, el abandono del mismo) y una arista lateral y otra basal para controlar el cintrado y carenado del plano de lascado (figura 12: 2). Otro de los núcleos presenta una configuración prismática unipolar. La mise en forme es similar a las anteriores. Plano de percusión cortical. El plano de lascado está delimitado por un plano cortical y una arista lateral. Las extracciones laminares han sido escasas debido a los reflejados de las extracciones (figura 12: 6). En un caso se aprovecha la morfología provocada por las diaclasas del nódulo y, con un pequeño plano de percusión realizado mediante pequeños levantamientos realizar las extracciones. Éstas se reflejaron, al menos, en su segunda serie extractiva (figura 13: 2) El último, de gestión prismática bipolar, presenta planos de percusión con ángulos oblicuos y una arista lateral para controlar el cintrado del plano de lascado. Una vez agotado para este tipo de gestión, tuvo una serie de extracciones de lascas en uno de sus laterales. El pequeño tamaño de las mismas nos hace pensar en una posible remise en forme del núcleo que no fue aprovechada o terminada (ver figura 12: 3). 

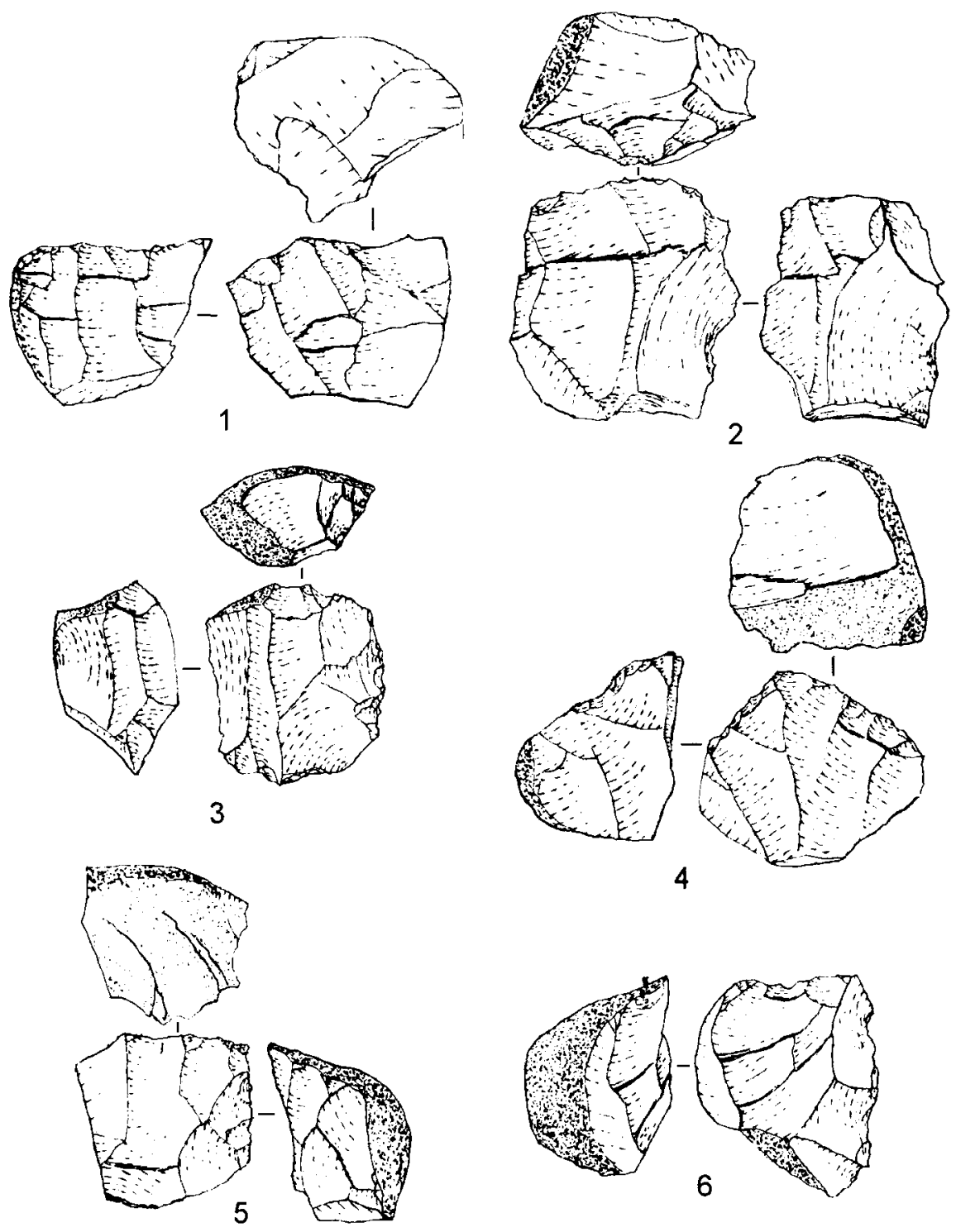

Fig. 12. Nivel 20c. 

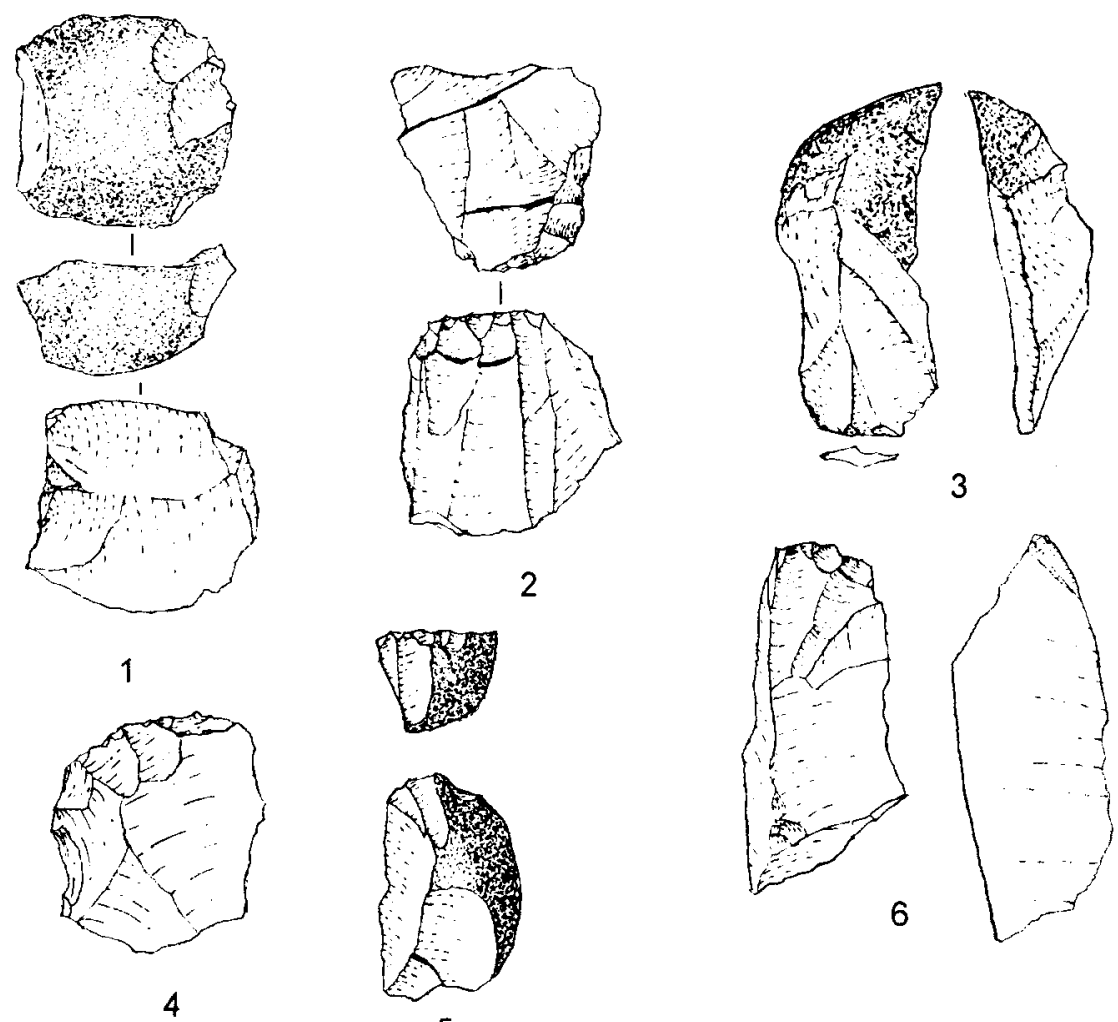

6
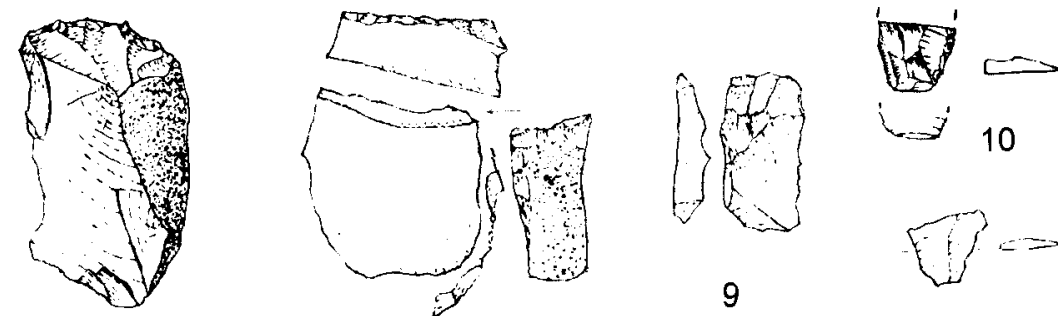

7

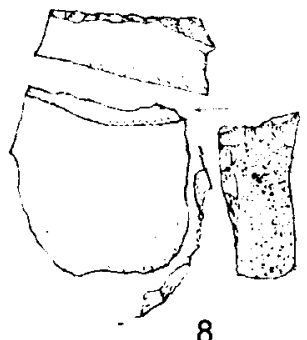

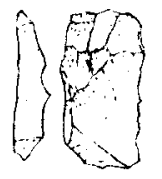

9

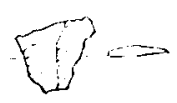

11

Fig. 13. Nivel 20c. 
El nivel 20c3b presenta un núcleo de hojitas tipo raspador carenado (ver figura 12: 5). El 20c3a otro núcleo similar al subnivel anterior (ver figura 12: 4). Aquí encontramos un pequeño núcleo Levallois de hojitas. El método empleado es el recurrente unipolar (ver figura 13: 1).

\section{b) Soportes}

Son escasos. El nivel 20c presenta dos hojitas de fase plena del débitage y un producto de acondicionamiento laminar indeterminado (figura 13: 9-11). El nivel $20 \mathrm{c} 1$ presenta una neoarista de núcleo, uno de los pocos ejemplares de los que disponemos por el momento en la colección (figura 13: 3).

\section{c) Útiles retocados}

Entre el material retocado de tipo Paleolítico Superior o fabricado sobre hoja $u$ hojita disponemos de cinco raspadores, de los que hay que destacar tres raspadores de tipo auriñaciense. Alguno de ellos muy típi$\mathrm{co}$, destacando un carenado inverso. Este nivel también presenta algún buril sobre fractura (figura 13: 4-8).

\section{NIVEL 20a/20b}

\section{a) Núcleo}

Este nivel presenta un núcleo prismático del tipo raspador carenado. La mise en forme es similar a los núcleos ya descritos. No hay preparación del plano de percusión, ni de los laterales del mismo, Para la convexidad distal se aprovecha un plano natural. El entretenimiento de la convexidad lateral se realiza a partir de la extracción de hojitas semicorticales (figura 14: 1).

\section{b) Soportes}

Se trata de un producto de acondicionamiento laminar indeterminado. (figura 14: 2). 
c) Útiles retocados

Junto a los útiles típicamente musterienses, destacan los raspadores "auriñacienses" y los buriles (figura 14: 3-4) como útiles de "tipo" Paleolítico Superior.
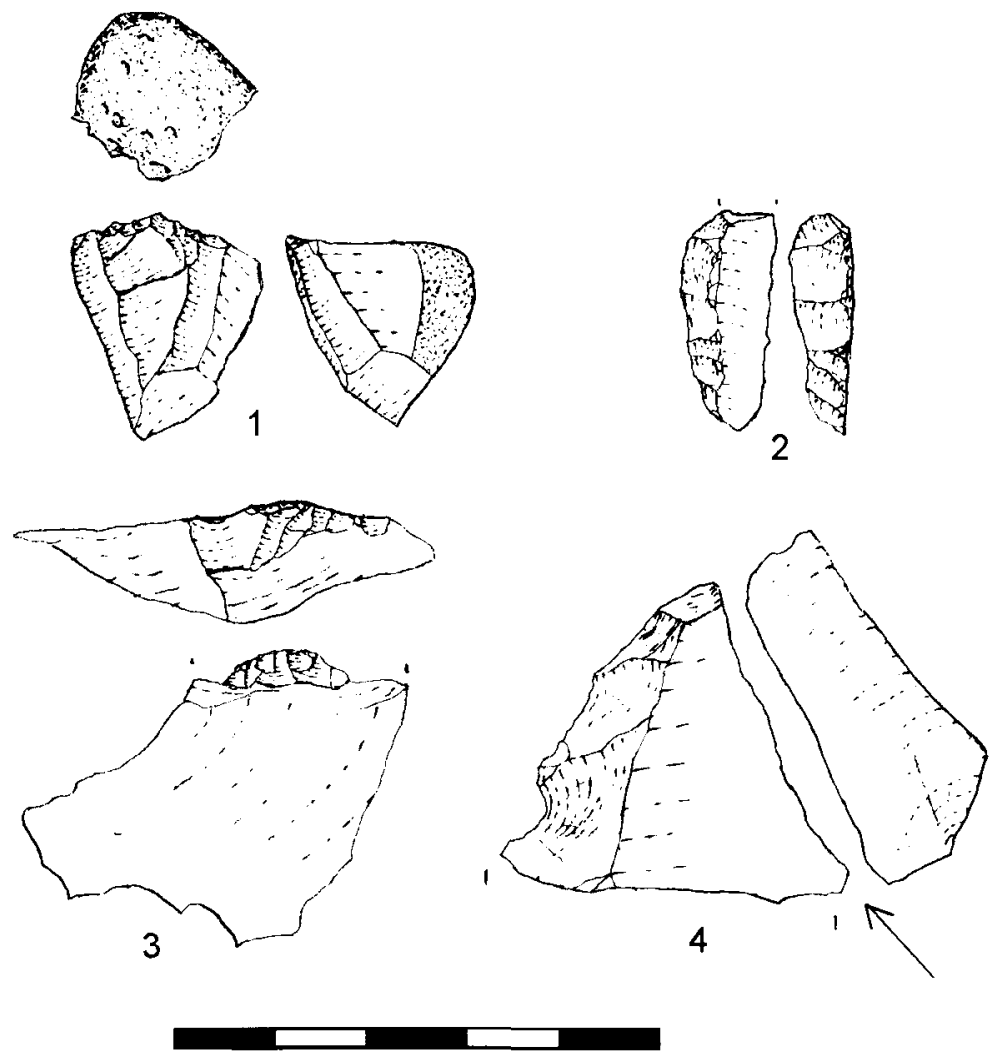

Fig. 14. Nivel 20a/20b. 


\section{RESUMEN TECNOLÓGICO}

\section{Materias primas}

La materia prima más empleada por los grupos que habitaron El Castillo en este momento fue la cuarcita, como se desprende de trabajos anteriores (Cabrera, 1984; Bernaldo de Quirós \& Cabrera, 1996). Con las nuevas excavaciones en la cueva la diferencia de esta roca frente al resto de las empleadas se ha acentuado aún más en la secuencia auriñaciense (niveles $18 b$ y $18 c$ ) y lo mismo parece suceder durante el musteriense (Cabrera et alli, 1996). Esto está provocado por la ausencia de selección que caracterizaba las excavaciones de principios de siglo.

En los niveles estudiados la mayoría de las piezas (y la totalidad de los núcleos) se elaboran sobre cuarcita del tipo C.1 en sus tres variedades posibles. Se trata de una cuarcita de grano muy fino y de buena calidad para la talla. El sílex es la segunda variedad más utilizada para la talla de hojitas. La mayoria se encuentran alteradas por desilicificación, aunque las que no lo están presentan grano fino y homogéneo, pudiendo ser opacas o no. Es el sílex denominado S.1 (Cabrera et alli, 1996).

El origen de las materias primas continua en estudio. Aunque el sílex de la colección antigua puede encontrarse en las proximidades del yacimiento hacia el norte (Vargas, Puente Arce) o al oeste (Tarriba). En todo caso todos son de origen local, ya que se encuentran a menos de $10 \mathrm{Km}$ de distancia en línea recta (Sarabia, 1999). El origen de la cuarcita puede encontrarse en los depósitos fluviales del Pas (muchos de ellos hoy desaparecidos), o en los restos de terrazas existentes en la vecina cueva de La Flecha (Freeman y González Echegaray 1968).

\section{Fase de preparación}

Hemos distinguido dos grupos de núcleos en los niveles estudiados: grupo 1, con núcleos a partir de nódulos y de explotación prismática (de gestión unipolar y bipolar) y el grupo 2, a partir de la reutilización de fragmentos de núcleos pertenecientes a otras cadenas operativas.

Esta etapa de preparación es necesaria en cualquier esquema de producción laminar (Inizan et alli, 1995; Tixier, 1984). Sin embargo, en los núcleos de la serie estudiada es muy escasa y poco estandarizada. Para la realización de los núcleos del grupo 1 se emplean aquellos nódulos que presentan una adecuación morfo-métrica al tipo de explotación que se va 
a realizar. La mise en forme es sencilla, con la preparación de uno o dos (si el núcleo es bipolar) planos de percusión. Los flancos del núcleo son los propios planos de fractura del nódulo o la zona cortical del mismo, aunque en algún caso se realizan aristas laterales o basales. El inicio de la explotación se realiza mediante entames corticales, no existiendo ninguna evidencia de otro tipo de extracción como son las aristas de núcleo, aunque sí se han constatados algunas neoaristas de núcleo para corregir problemas durante el débitage.

Por su lado, los núcleos del grupo 2 son realizados a partir de fragmentos de otros núcleos. Presentan una explotación prismática más "oportunista", es decir, aprovechan aquellas superficies que presentan las condiciones adecuadas para ser talladas bajo una organización laminar. Las series, por tanto, son cortas en cuanto al número de levantamientos realizados. No es raro que presenten varias zonas extractivas organizadas de forma ortogonal.

\section{Fase de explotación}

Los soportes conseguidos son hojas /hojitas (estas mas abundantes) bien caracterizadas. Presentan nervaduras paralelas al eje tecnológico y los levantamientos anteriores siguen la misma dirección. Los talones son lisos o puntiformes y con preparación en el anverso mediante abrasión o retoque. Esto unido a un plano de percusión oblicuo en el núcleo provoca el resalte del talón, consiguiendo el mismo efecto que la preparación en éperon.

Debido al tamaño de los nódulos empleados no existe apenas la fase de remise en forme de los núcleos, ya que realizar algún tipo de producto de acondicionamiento para reacondicionar el cintrado o el carenado de los núcleos invalidaría morfo-métricamente el mismo. La reactivación del cintrado se realizaría mediante lo que hemos denominado hoja de reactivado. Este tipo de producto de acondicionamiento controla el cintrado, permitiendo así el encadenamiento de las diferentes series recurrentes mediante una gestión en volumen del nódulo (Boëda, 1990). Sin embargo, el carenado del núcleo no se controla por este procedimiento. De hecho, el carenado en el método prismático unipolar no se controla y depende de la morfología original del núcleo. Cuando el carenado no es el apropiado el débitage se abandona. En el método prismático bipolar, el carenado se controla mediante las extracciones bipolares. Sin embargo, no existe una jerarquia de un plano de percusión sobre otro, ya que ambos son principales. 
El retoque de los soportes conseguidos es escaso, destacando tan solo

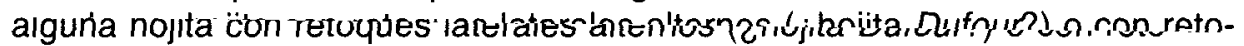
que abrupto.

\section{Modos de percusión}

El modo de percusión, dentro del estudio de las técnicas de talla empleadas en un conjunto arqueológico, es siempre un problema amplio y difícil de resolver. Para su identificación es necesario poner en marcha un amplio marco experimental de réplicas de los diferentes tipos de percusión para su posterior análisis y comparación con el conjunto arqueológico. Los estudios experimentales previos se han realizado sobre sílex (Pelegrin, 2000) y, en principio, sus conclusiones pueden ser extrapolables a los conjuntos de El Castillo en lo referente al silex y con algo mas de precaución sobre la cuarcita que son las materias primas más abundantes en el conjunto estudiado. Encontramos un modo de percusión principal en los materiales estudiados. Este es la percusión directa con percutor blando (orgánico). Este tipo de percusión se caracteriza por la ausencia de marcas de impacto en el talón, el talón es de reducido espesor, aparición de labio entre la cara bulbar y el talón, el bulbo es poco desarrollado o está ausente y los productos que se obtienen son delgados (Pelegrin, 2000). La percusión directa con percutor duro se constata en aquellas hojas de mayor tamaño, con talones de espesor mayor que los anteriores, punto de impacto marcado, estrías de percusión, etc.

\section{DISCUSIÓN}

Como ya dijimos en la introducción la presencia de producción laminar es un hecho conocido durante el Musteriense, sin embargo su cronología entre los EIO 8 y EIO 4, los colocaba cronológicamente distantes de los inicios del Paleolítico Superior, y faltando siempre una relación estratigráfica directa, por lo que esta producción solo permitía confirmar el conocimiento por parte de los Neandertales de esta técnica. Por otro lado la ausencia de hojas transformadas en útiles tipológicos del Paleolítico Superior dificultaba considerarlas como precedentes del mismo (Gamble 1999).

Junto a la habitual concepción en superficie de los esquemas de débitage de los conjuntos musterienses (Boëda, 1990), quedan constatados en los niveles Castillo 20 y 21 otros de carácter volumétrico. El objetivo de esta nueva concepción es, de forma mayoritaria, el débitage de hojitas. Esta concepción 
del nódulo no es nueva (Révillion \& Tuffreau, 1994;), pero no había sido constatada en momentos finales del Paleolítico Medio en el Suroeste de Europa y por otro lado su presencia se orientaba hacia la producción de hojas.

El método de débitage laminar que aparece en estos niveles de la cueva del Castillo es el prismático, con dos variantes: unipolar y bipolar. La mise en forme es escasa excepto en algunos núcleos muy característicos. Muchos de estos núcleos prismáticos unipolares recuerdan a la explotación tipo «raspador carenado" como los que podemos encontrar en niveles auriñacienses como el $18 \mathrm{c}$ y $18 \mathrm{~b}$ de El Castillo o el 7 de Morín. Preferimos emplear el término de prismático para este tipo de métodos, porque, aunque se alejen de las preparaciones del núcleo clásicas para el Paleolítico Superior, como son las del perigordiense superior y el magdaleniense (Bordes, 1968), ésta es reconocida como tal por otros investigadores para momentos iniciales del Paleolítico Superior (Inizan et alli, 1995)

Dos son los puntos divergentes entre el conjunto laminar de El Castillo $y$ el resto de conjuntos del occidente europeo:

a) La cronología: los conjuntos laminares conocidos del Oeste de Europa se encuadran en el EIO 8 a 4, al fin del Pleistoceno Medio, mientras que el conjunto aquí estudiado presenta una cronología situada entre los 40.000 BP del nivel Auriñaciense Transicional 18c (Cabrera, Pike TAy, Lloret y Bernaldo de Quirós. 2000), los 43.300 \pm 3800 BP (GiFA 92506) del nivel $20 \mathrm{~b}$ (Cabrera Valdés, Valladas, Bernaldo de Quirós et Hoyos, 1996) y los 69.000 BP de la base del nivel 21 (Rink, Schwarcz, Lee, Cabrera Valdés, Bernaldo de Quirós y Hoyos, 1997).

b) El modo de percusión empleado mayoritariamente en estos conjuntos es la percusión directa con percutor duro. En El Castillo el modo de percusión es el directo con percutor blando.

Las evidencias que presentamos sitúan una producción de hojas/hojitas en niveles musterienses situados estratigraficamente debajo del Auriñaciense Arcaico (Castillo 16 y $18 \mathrm{~b}$ y c) y con modelos de producción semejantes. En cierto modo reproduce la situación de Boker Tachtit (Marks 1992), y que hasta ahora era el único yacimiento que presentaba una clara evolución entre el Musteriense y el Paleolítico Superior. Sin embargo no deja de ser interesante que en Boker Tachtit las fases finales se relacionen con el Emirense y no con un Auriñaciense, siguiendo el proceso de transición tal y como se presenta en el Próximo Oriente, en donde el Auriñaciense es tardío.

La presencia de varias cadenas técnicas orientadas a la producción de hojitas en un nivel de Musteriense Quina con hendedores como es Castillo 20 
confirma nuestras hipótesis previas sobre la transformación de estas industrias hacia un Auriñaciense Arcaico y representa el nexo de unión entre este y el Musteriense. Como ya presentamos anteriormente (Cabrera, Pike Tay, Lloret y Bernaldo de Quirós. 2000) el Auriñaciense de transición de los niveles $18 b$ y $18 \mathrm{c}$ de la Cueva del Castillo presenta características propias de este conjunto industrial con raspadores en hocico y carenados, buriles -algunos múltiples-, hojas auriñacienses, etc. así como una importante presencia de raederas, la presencia de una azagaya nos permite valorar su existencia, y adjuntar las procedentes de la excavación de $\mathrm{H}$. Obermaier. La presencia de hojitas es un carácter que no debemos olvidar, pues si bien no parecen estar normalizadas dentro del «tipo Dufour» el carácter marginal de nuestra excavación con relación a la de $\mathrm{H}$. Obermaier no excluye que pudieran estar presentes. En cualquier caso algunas de ellas presentan macrohuellas que sugieren que pudieron haber sido utilizadas. La idea de un uso como parte de un útil compuesto sobre un fuste de madera (Lucas 2000) podria explicar las macrohuellas que observamos, aunque desgraciadamente no ha sido posible por el momento hacer un estudio de huellas de uso.

Las características de este nivel lo sitúan como intermediario entre el Musteriense y el Auriñaciense clásico. La presencia de esquemas operativos de producción de hojitas en los niveles 21,20 y 18 de Castillo estructuran una secuencia cuyo extremo seria la producción de hojitas característica de Auriñaciense 0 o Auriñaciense Arcaico (Kozlowski y Otte, 2000), mientras que el resto de la industria presente presenta caracteres en mosaico propios de ambas. Asi a la existencia de industrias transicionales como el Chatelperroniese, Uluziense, Bachkokiriense, etc. debemos unir el Auriñaciense de transición de Castillo $18 \mathrm{~b}$ y $18 \mathrm{c}$. La realidad de estos niveles obligan cada vez mas a excluir un origen extraeuropeo del Auriñaciense, que como hemos demostrado seria puramente local. Asi las características del nivel 16 de la cueva del Castillo ya indican un Auriñaciense Arcaico plenamente desarroliado, con autenticas hojitas Dufour, con lo que la secuencia se completaría. La presencia de restos fósiles del tipo humano de Neandertal en el nivel 20 de la Cueva del Castillo (Garralda Vandermeersch, Maureille 2000) confirma también nuestra hipótesis de una autoria neandertal para las industrias de transición -Auriñaciense 0 incluido- (Cabrera, Pike Tay, Lloret y Bernaldo de Quirós. 2000).

\section{AGRADECIMIENTOS}

Este trabajo esta incluido dentro del Proyecto BHA2000-0200 de la DICYT , del GDR 1945 «Comportements symboliques et tecniques des 
hommes du Pléistocene supérieur en Europe" del CNRS, y del Proyecto "Cambios sociales y condiciones paleoambientales en el Pleistoceno Superior de Cantabria: Monte Castillo y su contexto" del Plan de Promoción de la Investigación de la UNED,. así como de los diferentes proyectos de intervención arqueológica financiados por la Consejería de Cultura del Gobierno de Cantabria. Debemos agradecer también la colaboración del Ayuntamiento de Puente Viesgo. Asi como a J.M. Maillo y R. Yaguez por la realizacion de los dibujos.

\section{BIBLIOGRAFIA}

Bernaldo de Quirós, F. and V. Cabrera Valdes, (1996): Raw Material in the Paleolithic of Cueva del Castillo and in the Cantabrian Region, Non-Flint Stone Tools and the Palaeolithic Occupation of the Iberian Peninsula, Ed. N. Molloney, L. Raposo, M. Santonja, BAR International Series 649, pp. 21-32.

BOEDA, E. (1990): De la surface volumen: analyse des conceptions des débitages Levallois et laminaire. En Farizy (ed.): Paléolithique moyen rècent et Paléolithique supérieur ancien en Europe. Mémoires du Musée de Préhistoire d'lle de France, 3: 63-68.

Bordes, F. (1977): Que sont le Pre-Aurignacien et le Jabrudien?, Moshe Stekelis Memorial volume, Israel Exploratioin Society, Jerusalén pp. 49-55

- 1980, Le debitage Levallois et ses variantes, BSPF, 77/2, pp. 45-49.

Bosinski, G. (1966): Der paläolische Fundplatz Rheindahlen, Ziegelei Dressen-Westwand, Bonner Jahrbuch, 166, pp. 318-343.

CABAJ, V., V. SITLIYJ, (1994): The blade component in the Middle palaeolithic of Ukraine: origin and evolution, en REVILLON, S. ET A. TUfFREAU, 1994, Les industries laminaires au Paleolithique Moyen, Dossier de Documentation Archeologique n. 18 , CNRS, Paris.

Cabrera Valdés, V. (1984): El Yacimiento de la cueva de "El Castillo" (Puente Viesgo, Santander), Bibliotheca Praehistorica Hispana, 22, C.S.I.C., 485 pp.

Cabrera, V. et F. Bernaldo de Quiros (1990): Donnes sur la transition entre le Paleolithique Moyen et le Superieur a la Region Cantabrique; Revision critique. Paleolithique Moyen Recent et Paleolithique Superieur Ancien en Europe, Dir. C. Farizy, Memoires du Musee de Prehistoire d'llle de France $n^{\circ} 3$, Nemours, pp. 185-188.

Cabrera, V.; lloret. M. \& Bernáldo de Quirós, F. (1996): Materias primas y formas líticas del Auriñaciense Arcaico de la Cueva del Castillo (Puente Viesgo, Cantabria). Espacio, Tiempo y Forma, serie 1, 9: 141-158.

Cabrera Valdés, V., H. Valladas, F. Bernaldo de quirós eT M. Hoyos (1996): La transition Paléolithique moyen-Paléolithique supérieur à El Castillo Cantabrie: nouvelles datations par le carbone-14, Comptes Rendues Academie Sciences de Paris, 322, lia, pp. 1093-1098.

Cabrera, V., A. Pike tay, M. Lloret y F. Bernaldo de Quirós (2000): Continuity Patterns in the Middle-Upper Palaeolithic Transition in Cantabrian Spain, C.B. STRINGER, R.N.E BARTON and J.C FinLAYSON, Neandertals on the Edge, Oxbow Books, pp. 85-94.

Conaro, N.J. (1992): Tonchesberg ans its position in the Paleolithic Prehistory of Northern Europe, Monograph 20, Römisch-Germanisches Zentralmuseum Series, Bonn.

Freman, L.G. y J. GonzÁlez Echegaray, (1968): La industria musteriense de la Cueva de la Flecha (Puente Viesgo, Santander), Zephyrus, 18, pp. 43-61.

Gamble, C., (1999): The Palaeolithic Societies of Europe, Cambridge World Arcahaeology, Cambridge.

Garraldda, M.D., B. Vandermeersch, B. Maureille, (2000): Les hommes du moustérien récent et de l'aurignacien archaïque dans la région cantabrique (Espagne): nouvelles données et interrogations, Bull. et Mèm. de la Societe d'Anthropologie de Paris, N.S., T.12, p. 486.

InIZAN, M-L.; REduron, M; Roche, H. \& TIXIER, J. 1995: Technologie de la pierre taillée. C.R.E.P. p. 199.

KozLOWSKY, J.K. M. OTTE (2000): La formation de l'Aurignacien en Europe, L'Anthropologie 104, 
pp. 3-15.

LUCAS, G., (2000): Les industries lithiques de Falgeolet I (Dordogne): Approche economique, tecnologique, fontionelle et analyse spatiale, These Universite de Bordeaux I.

MARKS, A. (1992): Typological variability in the Levantine Middle Palaeolithic en DIBBLE, H. and P. Mellars (1992), The Middle Palaeolithic: Adaptation, behaviour and variability, University Museum Monograph 78, University of Pennsylvania. pp. 127-142.

Meigen, L. (1994): Le Paléolithique moyen au Proche-Orient: le phénomène laminaire, en ReviLLON, S. ET A. TUFFREAU (1994): Les industries laminaires au Paleolithique Moyen, Dossier de Documentation Archeologique n. ${ }^{\circ}$ 18, CNRS, París.

Pelegrin. J. (1995): Technologie Lithique: Le Châtelperronien de Roc-de-combe (Lot) et La Côte (Dordogne). Cahiers du Quaternaire, 20. p. 297.

- (2000): Les techniques de débitage laminaire au Tardiglaciaire: critères de diagnose et quelques réflexions. Valentin, B. \& Christensen, M. (eds.). Actes de la Table-Ronde Nemours 1997: 14 págs.

Revillon. S. ET A. Tuffreau (1994): Les industries laminaires au Paleolithique Moyen, Dossier de Documentation Archeologique n. ${ }^{\circ} 18$, CNRS, París.

Revillon. S., D. Cliquet (1994): Technologie du dèbitage laminaire du gisement paléolithique moyen de Saint Germain-des-Vaux/Port-Racine (Secteur I) dans le contexte des industries du Paléolitique moyen du Massif Armoricain, en Revillon, S. ET A. Tuffreau, Les industries laminaires au Paleolithique Moyen, Dossier de Documentation Archeologique n. ${ }^{\circ}$, CNRS, París.

Rink, W.J., H.P. Schwartz, H.K. Lee, V. Cabrera Vales, F. Bernaldo de Quirós and M. Hoyos (1995): ESR Dating of Tooth Enamel: Comparison with AMS ${ }^{14} \mathrm{C}$ at El Castillo Cave, Spain, Journal of Archaeological Science, 23, 6, 1196, pp. 945-952.

- (1997): ESR dating of Mousterian levels at el Castillo Cave, Cantabria, Spain, Journal of Archaeological Science, 24, pp. 593-600.

Rust, A. (1950): Die Höhlenfunde von Jabrud (Syrie), Karl Wacholz, Neumunster.

SARABIA, P.M. (1999): Aprovechamiento y utilización de materias primas líticas en los tecnocomplejos del Paleolítico en Cantabria. Tesis doctoral. Universidad de Cantabria. p. 842.

TIXIER. J. (1978): Notice sur le travaux scientifiques. Université de Paris X, Nanterre, Thèse de doctorat d'Etat, p. 117. 